\title{
Erratum to: Validation of the German version of two scales (RIS, RCS-HCP) for measuring regret associated with providing healthcare
}

Silvia C. Richner ${ }^{1}$, Stéphane Cullati ${ }^{2}$, Boris Cheval ${ }^{2 *}$, Ralph E. Schmidt ${ }^{3}$, Pierre Chopard ${ }^{2}$, Christoph A. Meier ${ }^{4}$ and Delphine S. Courvoisier ${ }^{2}$

\section{Erratum}

The authors of the original article [1] mistakenly omitted information in the Funding section of the Declarations.

As such, the authors would like to acknowledge that the study was supported by a grant from the Swiss National Fund (100019_166010).

\begin{abstract}
Author details
${ }^{1}$ Department of Internal Medicine and Specialties, Stadtspital Triemli, Zurich, Switzerland. ${ }^{2}$ Geneva University Hospitals, Geneva, Switzerland. ${ }^{3}$ University of Geneva, Geneva, Switzerland. ${ }^{4}$ Office of the Chief Medical Officer, University Hospital Basel, Basel, Switzerland.
\end{abstract}

Received: 6 April 2017 Accepted: 10 April 2017

Published online: 12 April 2017

\section{Reference}

1. Richner SC, et al. Validation of the German version of two scales

(RIS, RCS-HCP) for measuring regret associated with providing healthcare.

Health Qual Life Outcomes. 2017;15:56.

\footnotetext{
* Correspondence: boris.cheval@unige.ch

${ }^{2}$ Geneva University Hospitals, Geneva, Switzerland
} 